\title{
AL-IDARAH:
}

JURNAL PENGKAJIAN DAKWAH DAN MANAJEMEN

ISSN-E : 2654-4407 | ISSN-P : 2337-5035

http://jurnal.uinsu.ac.id/index.php/idarah/index

Vol. 9 No. 2 Juli-Desember 2021, hlm. 16-21

\section{KOMUNIKASI SPIRITUAL MEMBENTUK MANAJEMEN JIWA INDIVIDU DAN SOSIAL}

\author{
Muniruddin \\ Universitas Islam Negeri Sumatera Utara Medan, Medan, Indonesia \\ Email Korespondensi: Muniruddin@uinsu.ac.id
}

\begin{abstract}
ABSTRAK
Komunikasi dua arah saling berbagi informasi dan perasaan antara seorang individu dengan komunikan lainnya merupakan komunikasi inter personal dan setelah itu timbul komunikasi yang berkenaan dengan jiwa yang merupakan kekuatan non fisik dan sebagai curahan hati dengan sang Maha Pencipta Allah SWT. Manusia sebagai makhluk individu sekaligus sebagai makhluk sosial baru dapat mempunyai kekuatan apabila berhubungan dengan masyarakat sebagai bentuk sosialnya dan kepada kekuatan ghaib dari sang Maha Pencipta. Mengadakan hubungan dengan Tuhan sebagai kekuatan bathin. Apabila kedua-duanya terpenuhi maka akan mendapat kekuatan yang akurat dari luar yaitu fisik dan kekuatan dari dalam jiwa sebagai bentuk kekuatan spritual. Tulisan ini mengemukakan bagaimana kedua sumber kekuatan itu agar akurat menjadi kekuatan individu dan sekaligus kekuatan dalam pengembangan masyarakat. Hasil dari tulisan ini adalah komunikasi spritual merupakan komunikasi primer untuk menebar komunikasi lainnya dengan khalayak, karena jika mau berbagi informasi dengan banyak komunikan harus mempunyai tempat komunikasi yang kokoh dalam dalam diri individu sebagai komunikasi sipritual.
\end{abstract}

Kata Kunci: Komunikasi Spritual; Pengembangan; Jiwa Individu;

Masyarakat 


\section{PENDAHULUAN}

Arti spritual adalah dasar bagi tumbuhnya harga diri, nilai-nilai, moral, dan rasa memiliki. Ia memberi arah dan arti bagi kehidupan kita tentang kepercayaan mengenai adanya kekuatan non fisik yang lebih besar dari pada kekuatan diri kita; Suatu kesadaran yang menghubungkan kita langsung dengan Tuhan, atau apa pun yang kita namakan sebagai sumber keberadaan kita.1 Spiritual juga berarti kejiwaan, rohani, batin, mental, moral.

Komunikasi spiritual, menurut Nina W. Syam adalah komunikasi yang terjadi antara manusia dan Tuhan, atau dapat pula dipahami bahwa komunikasi spiritual berkenaan dengan persoalan agama. Artinya, komunikasi yang didasari nuansa-nuansa keagamaan. Agama mengajarkan kepada manusia, siapa manusia, apa tujuan hidup manusia dan mau kemana arah tujuan hidup manusia? Untuk menjawab itu semua, seseorang perlu melakukan komunikasi spiritual.

Dari pengertian yang dikemukan oleh Nina W. Syam di atas yang dimaksud dengan komunikasi spiritual adalah komunikasi antara manusia dengan penciptanya untuk mengenal dan melakukan proses berpikir tentang apa maksud dan tujuan manusia diciptakan. Dan untuk melakukan hal tersebut maka pendekatan yang paling mudah dan banyak dilakukan manusia adalah melalui pendekatan agama.

Adapun pengertian spiritual menurut penulis sendiri adalah sesuatu hal yang berhubungan dan mengandung makna yang berkenaan dengan jiwa, rohani ataupun batin yang mana jiwa atau batin tersebut merupakan pemberian dari Allah untuk memberi arah dan arti bagi kehidupan manusia. Maka komunikasi spritual dapat berarti berkomunikasi antara individu dengan Tuhan, seperti shalat, zikir, berdo'a dan lain sebagainya.

Komunikasi Spiritual mempunyai prinsip diantaranya adalah zikir dengan ismul a'zom ialah menzikirkan nama-nama Allah yang agung, seperti menzikirkan asma ul husna (nama-nama Tuhan yang baik). Saya memulai membaca al-Fatihah ini dengan menyebut nama Allah. Setiap pekerjaan yang baik, hendaknya dimulai dengan menyebut asma Allah, seperti makan, minum, menyembelih hewan dan sebagainya. Barangsiapa yang membaca isim ini "Ya Salam" terus menerus, Allah akan melindunginya dari semua bencana dan bahaya. Apabila Ya Salam dibaca sebanyak 160 kali untuk orang yang sakit, dengan izin Allah orang yang sakit tersebut akan segera disembuhkan dari penyakitnya. 
Membaca "ya salam" sebanyak 136 kali setiap hari, insya Allah, Allah akan menyelamatkannya dari setiap marabahaya dan akan disembuhkan dari penyakit. Demikianlah selanjutnya asma ul husna, jika diwiridkan akan mengandung hikmah sesuai artinya.

\section{METODE PENELITIAN}

Metode penelitian ini adalah penelitian kepustakaan (libraryresearch). Penelitian kepustakaan dilakukan dengan mengumpulkan berbagai sumber data relevan yang berasal dari sumber bacaan primer dan sekunder dari suatu topik permasalahan. Pada penelitian ini topik komunikasi spiritual membentuk manajemen jiwa individu dan sosial.

\section{PEMBAHASAN}

Komunikasi spiritual dapat dilakukan melalui amalan-amalan bathin, diantaranya, (1) Ash shalah, shalat secara etimologi ad du'a, sebagaimana firman Allah SWT : Washalli 'alaihim, artinya berdo'alah untuk mereka. Sedangkan shalat secara terminologi ialah beberapa ucapan dan perbuatan yang dimulai dari takbiratul ihram dan di akhiri dengan salam dengan syarat syarat tertentu. Dalam mendirikan shalat di awali dengan niat yaitu Qoshdusysyai in muqtarinam bifi'libi, niat ialah menyengaja sesuatu perbuatan, menentukan serta penyerahan jiwa kehadirat Ilahi. Pada rukun fi'ly dalam shalat ada thumakninah, yaitu konsentrasi tenang dalam keheningan, berhenti sejenak sambil menghayati makna bacaan yang sedang diucapkan dan mencapai khusyu' (konsentrasi penuh jiwanya ke hadhirat Allah), (2) Ad Du'a, Allah SW'T menyuruh hambanya berdo'a, karena do'a seorang hambanya di dengar oleh Allah SWT dan barangsiapa yang enggan berdo'a kehadirat Allah, maka Allah murka kepadanya dan dicap dia sebagai orang yang sombong dan akan ditempatakan pada neraka jahannam dalam keadaan yang sangat hina.

Adapun fungsi-fungsi doa diantaranya, (1) Menolak takdir, sabda Rasulullah SAW : tidak ada yang dapat menolak takdir kecuali do'a, dan tidak ada yang dapat menambahi umur kecuali berbuat kebaikan. HR. Tirmizi, (2) Peninggi derajat di akhirat, rasulullah SAW bersabda: ada dua orang yang masuk ke dalam syurga dan keduanya mengamalkan amal sholih yang sama lalu salah seorang dri mereka melihat shahabatnya lebih tinggi derajat syurganya darinya kemudian dia berkata: waha Tuhanku, mengapakah Engkau berikan hal itu kepadanya sedangkan amal kami sama..? firman Allah : dia suka berdo'a kepadaKu, sedangkan kamu tidak, (3) Senjata 
para nabi dan orang yang beriman, sabda Rasulullah SAW dari As Saukani dari Abu Abdillah, katanya Nabi bersabda : do'a itu senjata orang beriman, tiang ajaran an cahaya seluruh langit dan bumi.

Dari Ibnu Fadhdhal dan dari Ali Ridha beliau berkata kepada sahabatsahabatnya: gunakanlah oleh kalian Silahul Anbiya' (senjata para Nabi), maka beliau ditanya apa silahul anbiya' itu.? Beliau menjawab; silahul annbiya' adalah do'a. (4) Penolak bala, Ali Bin Abi Thalib berkata: tolaklah gelombang bala bencana darimu dengan do'a, sebelum datagnnya bencaa itu, maka demi Tuhan yang telah membelah biji dan menegar jiwa, sungguh bala itu lebih cepat datgnnya kepada orng yang beriman dari trcurahnya air bah dari dataran yang tinggi ke dataran yang rendah, dan lebih cepat dari terjangan kuda kuda perng. Allah maha suci mempunyai banak cambuk dan siksa, apabila hal itu akan turun kepadamu tolaklah denan do'a, karena tidak ada yang dapat menolak bla' selain do'a. (5) Obat segala penyakit, dari Muhammad bin Muslim dia berkata; saya berkata kepada Abu Ja'far, Rasulullah SAW pernah mengatakan bahwa: pada biji yang hitam ini darinya terkadaung obat bagi setiap penyakit selain racun beliau berkata, ya. Kemdian beliau bersabda: maukah kukabarkan kepadamu sesuatu yang mengandung obat bagi setiap penyakit dan rcun sekalipun..? Muhammad menjawab, ya beliau berkata: itu do'a.

Syeikh Abu Sa'id al Kharraz menyatakan : Apabila Allah hendak melindungi seseorang, maka dibukakanNya pintu zikirnya, jika kelezatan zikir telah terasa, maka dibukakanNya pintu pendekatan (taqorrub) dan diangkatkanNya pula martabatnya dihadapan manusia. Sesudah itu didudukkanNya di atas tauhid, diangkatkanNya hijab tabir sehingga ia mempunyai pandangan kasyaf, kemudian dimasukkanNya ke dalam darul fardaniah (alam rahasia), tersingkaplah dinding kemuliaan dan ą̧bmah kebesaran, tatkala pandangannya menembus ke alam jalal dan 'azmah, maka tinggallah dia tanpa dia, jadilah ia fana beberapa saat tenggelam dalam menikmati rahasia kebesaran Allah dan terus dilindungiNya. Hati yang tentram dengan berzikir, bukanlah sekedar hanya mengucapkan begitu saja, namun harus diiringi dengan penghayatan apa yang diucapkan, orang yang berzikir telah mengenal Allah, mengetahui kebesaran Allah, takut kepada azab dan murkaNya. 


\section{KESIMPULAN}

Komunikasi spritual adalah berkomunikasi antara individu dengan Tuhan, seperti shalat, zikir, berdo'a dan lain sebagainya dalam bentuk ibadah mahdhah (ibadah pribadi kepada Tuhan). Komunikasi spritual selain bermanfaat untuk diri pribadi juga sebagai komunikasi inter personal dalam bentuk dua arah, yaitu dari dalam diri sendiri dan dari diri sendiri kepada sang Maha Pencipta.

Dengan adanya komunikasi spritual berhasil, maka terbangun pula bentuk inter personal dan massa, karena khalayak adalah kumpulan dari personal yang bergabung menjadi satu jamaah atau kelompok dan menjadi mengembang dalam perluasan komunikasi kelompok dan massa. Justru mulailah dari diri sendiri sebagai bentuk komunikasi intra personal, seterusnya menjadi interpersonal secara spritual dan pada gilirannya dapat mengembangkan masyarakat yang ta'abbudy.

\section{DAFTAR PUSTAKA}

Fuad Said. (2005). Hakekat Tarikat Naqsyabandia. Pustaka al Husna Baru, Jakarta.

Aliyah Abidin. (2009). al Luju' Ilallah Ad'iyatun Wa A₹karun, Terj. Do'a dan Zikir Makna dan Khasiatnya. Pustaka Nuur, Semarang.

Fathir Muhammad.( 2015). Drikir Asmaul Husna, Zikir asmaul Husna untuk kesejabteraan, kesukses dan kesehatan, Adibintang, Jakarta.

Imam Bukhari, Shohih Bukhari. Terj. H.Zainuddin Hamidy et.all Jld-IV, Widjaya, Jakarta.

M. Hermawansyah. (2015). Membuka Rahasia Manfaat Zikir Asmaul Husna Berdasarkan al Qur'an dan As Sunnah. Kunci Iman, Jakarta.

Mimi Doe dan Marsha. (2001). 10 Prinsip Spiritual Parenting: Bagaimana Menumbubkan dan Merawat Sukma Anak Anda. Bandung: Kaifa.

Ujang Saefullah. (2013). Kapita Selekta Komunikasi Pendekatan Budaya dan Agama. Simbiosa Rekatama Media, Bandung. 


\section{AL-IDARAH, Volume 9, No.2, 202121}

Muhammad bin Ibrahim. (2012). Ensiklopedi Islam al Kamil, Jakarta,.

Muhsin Labib, Kamus Do’a, Tinta Publisher, Jakarta, 2011

Syeikh Muhammad Bin Ibrahim bin Abdullah at-Turwaijiri. (2015).

Ensiklopedi Islam al Kamil, Terj. Achmad Munir Badjeber, M.Ag. Jakarta:

Darussunnah. 
AL-IDARAH, Volume 9, No.2, 202122 